\title{
SAÚDE E DOENÇA NA AMAZÔNIA: CONTRIBUIÇÕES DA INTERDISCIPLINARIDADE
}

\section{APRESENTAÇÃO}

A Amazônia brasileira e suas fronteiras internacionais apresentam um cenário diverso e multifacetado de culturas, biomas e sujeitos sociais. Rica em sua diversidade biológica e plural em sua sociodiversidade, a realidade amazônica compõe complexas relações para se pensar o fenômeno saúde e doença. O perfil epidemiológico dessa região, ainda hoje, aponta para a convivência com doenças transmissíveis, de fácil controle, e outros problemas sanitários de diversas complexidades, dadas as dimensões ecológicas e culturais da floresta.

Fortemente impactada pelos projetos de desenvolvimento, a floresta e a paisagem dos rios têm reagido e, cada vez mais, modificado a forma como se adoece e morre na Amazônia. O controle do adoecer e morrer é imprescindível da complementariedade entre os saberes dos conhecedores das práticas de cura tradicional e dos conhecimentos da biomedicina ocidental e de suas tecnologias. É na rica relação entre os diferentes sujeitos sociais, suas culturas, posições políticas e sociais que esse dossiê busca levar o leitor para entender a saúde, a doença e as suas múltiplas relações interdisciplinares.

Ana Lídia Nauar Pantoja faz um estudo exploratório com base no método biográfico e da história oral, e toma como ponto de análise a biografia de Francisca dos Santos Tembé. O estudo busca refletir sobre as tensões entre os saberes (e poderes) entre os especialistas médicos e os especialistas ditos tradicionais. O enfoque do estudo busca mostrar como esses saberes, historicamente postos como subalternos, continuam resistindo, apesar dos processos de hegemonia da medicina e de suas práticas. Nesse contexto, a autora enfatiza a necessidade das políticas públicas assumirem uma posição de valorização desses saberes, já que se trata de saberes ancestrais, transmitidos de geração em geração, que sustentam as identidades das populações indígenas e de outras comunidades que compõem a Amazônia brasileira.

Aristóteles Guilliod de Miranda e José Maria de Castro Abreu Júnior lançam mão da análise das biografias comparadas de duas importantes médicas do Estado do Pará pioneiras no ensino de cardiologia e do uso do aparelho eletrocardiograma - Maria do Carmo Sarmento Carvalho e Bettina Ferro de Souza -, formadas nos anos de 1930, pela Faculdade de Medicina e Cirurgia do Pará. Ao analisar as trajetórias de ambas as mulheres, os autores analisam o "esquecimento" que levou a sociedade de cardiologia e os mais destacados médicos da área a silenciarem o pioneirismo de Maria do Carmo Sarmento de Carvalho e destacar a trajetória de Bettina Ferro. Ainda que ambas tenham sido mulheres e médicas, segundo os autores, é a trajetória política de Maria do Carmo e seu percurso marginal, fora dos padrões ideais da classe médica, que possibilita que alguns sujeitos sociais, "escapa (pem) aos cânones de memória" como foi o caso de Maria do Carmo Sarmento.

No cenário da Belle Époque, em Manaus, Márcio de Carvalho e Silva e Keith Valéria de Oliveira Barbosa analisam como a malária tomou proporções epidêmicas no período republicano. Em um cenário de transformação urbana e modernização, ao passo em que a cidade era saneada, a epidemia da malária e da febre amarela se intensificava, assim como o discurso médico-sanitarista também se transformava. Reconhecendo o âmbito social da doença, os autores procuram mostrar seus agentes sociais e, a própria noção da doença, como decorrente dos determinantes políticos e sociais do seu tempo. A produção do discurso médico compõe oscilações entre a defesa da teoria dos miasmas, 
em razão das condições insalubres da cidade, sobretudo, do curso dos igarapés (discurso mais presente nos últimos anos da época provinciana), e a defesa do caráter científico do vetor Anophele, que sugeria a profilaxia sanitária da cidade (já no século XX). Em ambos os discursos buscava-se justificar as mudanças na paisagem urbana da cidade, formalizando uma interpretação híbrida sobre a doença.

Com base em sua experiência de campo, no período em que eclode a pandemia da Covid-19 no Brasil e no mundo, Petrônio Potiguar relata como o plano de isolamento social na aldeia Mapuera, localizada na fronteira entre o Pará e o Amazonas, foi tensionado por questões religiosas. O cenário da Covid-19 leva o pesquisador a questionar-se acerca do papel do antropólogo perante essa realidade, denominada por ele, "no olho do furação" da Covid-19. Com a entrada de 45 pessoas, inesperadamente, na aldeia, o plano de isolamento construído com algumas lideranças e o cacique geral é desconsiderado e a despreocupação com os riscos atribuída à "fé em Deus". No entanto, mesmo em contexto adverso, o autor relata que o plano inspirou a adoção de medidas nacionais para os DSEI's do Brasil, sendo adotado parcialmente e com relativo controle da doença, o que reforça, no autor, a ideia de que são imprescindíveis ações conjuntas, interdisciplinares e dialógicas com os indígenas para que o enfrentamento da Covid-19 seja exitoso.

Danieli Pinto Silva e Tabita Fernandes da Silva apresentam impasses e diferenças linguísticas no contato entre a comunidade bragantina e os médicos cubanos estabelecidos na cidade de Bragança (PA) em virtude do Programa Mais Médicos. As pesquisadoras mostram que o contato linguístico espanhol/português lançou mão de estratégias e soluções variadas na interação da prática clínica. A pesquisa mostra que se construiu em Bragança uma relação que lançou mão de termos linguísticos populares, mímicas, movimentos e variedades regionais da língua em nome do atendimento de saúde humanizado.

Recorrendo à história da saúde pública, Edivando da Silva Costa estuda o Serviço Especial de Saúde Pública (SESP) e o modelo hospitalar posto em prática nas cidades de Breves e Santarém entre 1942 e 1945. Criado como agência binacional de cooperação entre Brasil e Estados Unidos, o SESP ficou conhecido por implementar um modelo de atenção à saúde horizontalizado. $\mathrm{O}$ arranjo político dos interesses pela floresta no contexto da guerra e dos anseios do governo Vargas para a região viabilizaram estruturas de saúde pública até então desconhecidas pelas populações do arquipélago do Marajó e do oeste paraense.

No artigo "Sexo é só pra quem pode pagar: um diálogo com o cotidiano da prostituição no Pará", Augusto César Pinto Figueiredo debate através do recurso da história oral as memórias sobre as dinâmicas das trabalhadoras do sexo em áreas de barragens na Amazônia. Por meio de discussão teórica e trabalho de campo o texto descreve o cotidiano da prostituição em meio a questões culturais, psicológicas e de ordem prática da vida material.

Erilana Silva Pacheco, Josiane Silva de Lima Azevedo, Yrlane Paes Ferreira, Sylvia de Fátima dos Santos Guerra e Márcia Cristina dos Santos Guerra expõem dados epidemiológicos sobre a Leishmaniose visceral, doença endêmica no Brasil. A alta incidência da doença nas regiões norte e nordeste, apresentada de forma detalhada em gráficos e tabelas, indica o crescimento da doença em locais que vivenciaram redução de áreas de florestas, facilitando a entrada da Leishmaniose nos centros urbanos. Ou seja, uma leitura pela epidemiologia que revela também as faces das condições sanitárias e de acesso à saúde nas regiões do país. 
Esperamos que aqueles que tenham encontrado este dossiê possam se beneficiar da interdisciplinaridade na área de estudos em saúde como tônica e possibilidade para tematizar nossos problemas e dinamizar nossos saberes na Amazônia.

\section{Os organizadores}

\section{Vanderlúcia da Silva Ponte}

Antropóloga, Professora Adjunto da Faculdade de História, Campus de Bragança, do Programa de Pós-graduação em Linguagens e Saberes da Amazônia (UFPA) e do Programa de Educação Escolar Indígena (UEPA/UFPA/UFOPA/UNIFESSPA). Líder do Grupo de Estudos e Pesquisas Interculturais Pará-Maranhão (GEIPAM). E-mail: vantutorapa@gmail.com.

\section{Érico Silva Muniz}

Historiador, Professor Adjunto da Faculdade de História, Campus de Bragança, e do Programa de Pós-Graduação em Linguagens e Saberes na Amazônia da Universidade Federal do Pará (UFPA). Membro do Grupo de Estudos e Pesquisas Interculturais ParáMaranhão (GEIPAM). E-mail: ericosilvamuniz@gmail.com.

\section{Rômulo de Paula Andrade}

Professor do Programa de Pós-Graduação em História das Ciências e da Saúde da Casa de Oswaldo Cruz, na Fundação Oswaldo Cruz. Pesquisa e orienta temas relacionados aos impactos ambientais e sanitários de projetos de desenvolvimento na região amazônica, além de trabalhos sobre a história do combate à fome no país. E-mail: romulopa@hotmail.com

\section{Tânia Chaves}

MD, Ph.D, Médica Infectologista, Docente da FAMED/UFPA. Pesquisadora em Saúde Pública/IEC/SVS/MS/Vice-Coordenadora do Programa de Pós-Graduação em Epidemiologia e Vigilância em Saúde do Instituto Evandro Chagas/SVS/MS. Membro e Consultora das Sociedades Cientificas Brasileiras de Imunizações/ e de Infectologia. Presidente da Sociedad Latino Americana del Viajero. E-mail: tania.chaves@uol.com.br 